AUTHOR:

Dr Bronwyn Claudia Swartz ${ }^{1}$ iD

Dr Lucrecia Zinobia Valentine ${ }^{1}$

Dr Desiree Virginia Jaftha ${ }^{1}$

AFFILIATION:

${ }^{1}$ Cape Peninsula University of Technology, South Africa

DOI: http://dx.doi. org/10.18820/2519593X/pie. v40.i1.6

e-ISSN 2519-593X

Perspectives in Education

2022 40(1): 96-111

PUBLISHED:

04 March 2022

RECEIVED:

14 August 2021

ACCEPTED:

31 October 2021

\section{Participatory parity through teaching with Telegram}

\begin{abstract}
The COVID19 pandemic thrust emergency remote teaching (ERT) into the global spotlight and thereby undeniably changed aspects of the higher education (HE) landscape. For a developing country such as South Africa (SA), the use of the mobile instant messaging (MIM) application (app) called Telegram represents a practicable solution to overcome historical socio-economic challenges faced by certain demographic groups of limited or restricted access to devices and data. Against this backdrop, a Telegram teaching intervention was developed by two lecturers in the Engineering Faculty at a University of Technology (UoT) in SA to deliver curriculum content and engage with students in a low-tech, low-cost/low-data usage manner, and consequently to widen access to education, promote inclusivity and thereby facilitate student access, retention and success. This study explored student perceptions of the MIM app being used as a primary vehicle to deliver succinct instructional materials and facilitate class activities to offset the lack of faceto-face classes in a multimodal and flexible curriculum delivery approach. Following the completion of the Telegram teaching intervention, a mixed method approach was used that included two online surveys measuring different aspects of the same project $(n=34$ and $n=32)$ and a focus group interview $(n=6)$. Three research lenses suggested by Fraser (2008) were used to evaluate student perceptions of the usefulness and (dis)advantages of Telegram. These lenses were: (1) redistribution (of resources), (2) recognition (related to social status) and (3) representation (who can act/say/ challenge in an academic environment). Ethical clearance was obtained from Cape Peninsula University of Technology's Ethics committee. Initial results indicate that using the Telegram app for teaching and learning was successful. Significantly, the app allows for the emergence of a socially just online classroom environment and an inclusive and enabling learning experience for the students during a very disruptive and fearful time in the world's history.
\end{abstract}

Keywords: Mobile instant messaging applications; remote learning; learning design; higher education.

\section{Introduction}

The COVID-19 pandemic propelled transformation in higher education (HE) towards remote education and evolutions in technology have contributed to the emergence of new and innovative pedagogical approaches (Kauppi et al., 2020). While there is an increased interest in understanding how universities responded to the pandemic (Bao, 2020; Greene, 2020; Huang et al., 2020; Lim, 2020; QS, 2020), fewer studies reflect on the abrupt switch to online teaching, 
especially the use of mobile learning and its impact on students and society. Gronseth and Zhang (2018) advanced that mobile instant messaging (MIM) apps can be used as part of an inclusive digital learning strategy. They posit that through simple text messages and communication between students and lecturers, the apps can link students to their lecturers, which enhance academic achievement. Moreover, various studies reported that MIM apps foster communication and collaboration among peers (Nitza \& Roman, 2016), enhance social presence (Tang \& Hew, 2017), improve access to resource materials and provide peer support (Timmis, 2012). Against this backdrop, this study explores an MIM app teaching intervention that was developed by lecturers at a University of Technology (UoT) as a tool to teach students, facilitate and engage in class interactions, and transfer content during the national lockdown in South Africa, when face-to-face teaching was not possible.

\section{Fraser's framework for social justice}

Opotow (2011) describes social justice as... "the fair distribution of resources and benefits to all members of a society, is an abstract ideal that applies the concept of justice broadly". The foregoing discussion draws attention to the value that real-time social media tools (e.g. MIM apps) can contribute during unsettling times, such as the COVID-19 pandemic. The ease of use of MIM apps is an attribute that has expanded its popularity across the educational sector, in and outside the classroom. One such app is Telegram.

To contemplate our Telegram teaching intervention, we adopted Fraser's (2008) justice framework. Fraser (2008) proposed three dimensions that can be used when researching a community of learners. The dimensions are: (1) redistribution, (2) recognition and (3) representation, which we refer to as the 3 Rs.

Literature in educational development shows Leibowitz et al. (2012); Leibowitz and Bozalek (2016) utilising Fraser's (2008) framework for social justice. Discussing the first dimension, Fraser (2008) suggests that economic structures may impede some members of a community from fully participating. She explains that when members of a community do not have resources to interact as peers, they suffer from distributive injustice or maldistribution. In this instance, "redistribution" is the corrective action to be taken. In the context of the UoT where this study took place, at the onset of the lockdown, not all members of the community had equal access to adequate devices and/or sufficient data to allow them to continue to partake in class activities.

With reference to the second dimension, Fraser (2008) argues that when institutionalised hierarchies of cultural value prevent members of a community from interacting in terms of parity, the hierarchies of cultural value deny members of a particular community a prerequisite standing in it. As a result, the alienated members suffer from status inequality or misrecognition. Aside from historical socio-economic challenges, a distinct characteristic of the student community in the programme where this research took place is that they are parttime students. Thus, the research participants may be described as non-traditional students who have already reached physical maturity, are older in age, live off-campus and have responsibilities related to family and/or employment (Putri \& Elihami, 2021). When compared to the general UoT student population, the demographics of part-time students are regarded as different. Lee (2017) asserts that part-time students are at a significantly higher risk for premature withdrawal from their studies than their full-time peers, due to conflicting priorities. Moreover, access to institutional resources such as financial aid or support services such as 
tutor-support, is also limited for part-time students. Therefore, premised on Fraser's (2008) description of the second dimension, the research participants were considered vulnerable to discrimination by institutionalised hierarchies of cultural value. She advances "recognition" as a corrective action to overcome challenges associated with status inequality or misrecognition.

Finally, Fraser (2008) deliberates on a third dimension, elucidating when decision rules inhibit members of a community from participating as equal partners in social interaction and deny them an equal voice in community discussions and democratic decision-making, they suffer from political injustice or misrepresentation. In our context, this entailed recognising who is allowed to act, provide opinions or challenge in our academic environment. This was particularly significant at the commencement of lockdown when acknowledging the student voice became critical. During this time, from March to April 2020, several authors (Gachago \& Cupido, 2020; Agherdien, 2020; Rowe, 2020) argued that the only way to sustainably continue an academic programme was to consult with students during planning, to do what is best and realistic for all. By doing this, "representation" is ensured.

Thus, a research question arose from the preceding discussion, which is: "Can an MIM app, such as Telegram be used as a pedagogical tool to achieve participatory parity in an online classroom environment?" Accordingly, the objective of this research is to determine if the Telegram app can be used as a pedagogical tool in a manner that assures participatory parity in an online classroom environment.

\section{Literature review}

To secure a deeper understanding of the research area to meet the objective of this study, literature is presented on the four important areas that underpin the research question, namely "technology for participatory parity", "learning in lockdown", "mobile instant messaging applications" and "Telegram for teaching and learning". This is presented in the section that follows.

\subsection{Technology for participatory parity}

Bozalek (2016) argues that social justice may be equated to participatory parity. She refers to participatory parity as the ability to interact socially on an equal footing with peers. She argues that numerous social arrangements framed by Fraser's 3Rs are required for the inception of participatory parity (or social justice). Significantly, she points out that the three dimensions are entwined and flow into each other, however, importantly, each dimension needs to be addressed separately.

Discussing emerging technologies for teaching and learning, Bozalek (2016) points out that although sophisticated technologies are portrayed as a feasible solution to teach in the resource-rich global north environments, in resources-constrained contexts (such as the UoT where this intervention took place), careful consideration needs to be taken to ensure social justice in the classroom environment. Against this backdrop several researchers such as Oyewole, Animasahun and Chapman (2020), Gon and Rawekar (2017) and So (2016) explored the use of MIM apps to teach. For developing countries such as South Africa (SA), the use of MIM apps represents a practicable solution to overcome challenges of restricted access to devices and limited data as a result of historical socio-economic difficulties. Significantly, research by Patnaik and Swartz (2020) on using MIM apps to teach in lockdown found there are several positive implications of using these, such as simplicity, quick and easy 
access for students to course work, swift feedback, self-motivation and time management. Thus, using the $3 R$ s as a guide, this study set out to explore the usefulness of an MIM app teaching intervention when face-to-face teaching was not possible.

\subsection{Learning in lockdown}

The Coronavirus disease (COVID-19) was declared a pandemic by the World Health Organization (WHO) on 12 March 2020 (WHO, 2020). Viner et al. (2020) reported that in an estimated 107 countries across the globe, educational institutions were closed as a measure to curb the spread of COVID-19.

Van Aard and Sibanda (2021) reported that in SA, some students were forced to return home during the national lockdown. They advanced that "home" for some of these meant a remote place without any technological infrastructure, where the nearest place with internet reception was a library a few kilometres away. For other students, "home" is a low-income, densely populated township on metropolitan outskirts, not conducive to studying. Moreover, in several homes where resources were available, they needed to be shared with other family members. Van Aard and Sibanda (2021) depict this period as one characterised by crippling fear, anxiety and prejudicialness, because of the pandemic.

Thus on 30 April 2020, when the South African Minister of Higher Education announced "leave no student behind" (Parliamentary Monitoring Group, 2020), it triggered the exploration of various forms of technology by higher education lecturers in an attempt to continue teaching. This included considering low-technology remote teaching aids such as MIM apps. While MIM apps have not been commonly used for teaching and learning prior to 2020 (Fataar, 2020), several studies (Silver et al., 2019; So, 2016; Kukulska-Hulme et al., 2011) have argued that they can be used successfully. However, there is a paucity of information on the extent to which MIM apps foster participatory parity in online classroom environments. Thus, this research study sets out to empirically examine this.

\subsection{Mobile Instant Messaging (MIM) applications}

Mobile instant messaging enables smartphone and/or mobile phone users to engage in instant messaging and provides a platform for users to engage socially with one another on these devices (Ogara, Koh \& Prybutok, 2014). Silver et al. (2019) purport that apps on smartphones and mobile devices have evolved from mediocre to sophisticated communication tools with the ability to aid remote learning. They add that the use of mobile devices has increased worldwide and there is no question that a large percentage of students at HE institutions in SA own at least one such device. Significantly, smartphones and mobile devices can be used to access internet-based educational platforms via WiFi connectivity on campus, at work and in homes.

An international study about adult learners at higher education institutions by KukulskaHulme et al. (2011) uncovered that smartphones serve as communication, business and learning tools for them, across several environments including academic, social, entertainment and workplaces. Moreover, numerous research studies have been published to support the use of messaging systems in the delivery of educational activities since these MIM apps are versatile regarding them being able to be used for teaching and learning support as well as communication and administrative support (So, 2016). 


\subsection{Telegram for teaching and learning}

Educational institutions are compelled to stay abreast with rapid and steady global development in technology (Mahmood, 2021) of which Telegram is an application used for teaching and learning. Sari (2017) describes Telegram as a multi-device compatible MIM app consisting of a low-cost platform allowing real-time exchange of multimedia. Additionally, this low-cost app can use WiFi, thus requiring no additional data costs for instant messaging when in a WiFi area. In an educational context, users of the app can create multiple class groups to allow participation in discussions and forums. A particularly useful feature of the app is the poll function that allows educational facilitators to offer student quizzes aside from using it for polls. The app integrates phone numbers from the device's phone book, thus there is no need for usernames and passwords. Importantly, Telegram also supports offline messaging features. This allows offline devices to retrieve saved messages as soon as a device is switched on or comes in the range of network coverage (Bere, 2012).

Notably, a recent study by lqbal et al. (2020) reported multiple utilities of the app, including easy access to educational resources and the ability to add unlimited members, as well as files in all formats and sizes. In their study with medical students, they found the app assisted students to engage in collaborative learning while maintaining their wellbeing and ensuring their security. However, they also reported some drawbacks, i.e. a complex interface, information overload and a tendency to distract the students, causing time wastage while studying. With this in mind, this study set out to determine if the Telegram app can be successfully used as a tool to achieve participatory parity in an online classroom environment.

\section{Methodological approach}

At the commencement of the national lockdown in SA in March 2020, across the country, student feedback was solicited by several universities (Shoba, 2020) to determine the difficulties that students were experiencing due to the lockdown. A survey conducted at a UoT where this research took place confirmed that the institution's students experienced the same challenges that were highlighted at the national level, such as restricted access to computers, laptops and advanced smartphones. Ostensibly, the greatest challenge was student access to data to continue the academic programme. Thus, following the Minister of Higher Education's announcement in April 2020 to "leave no student behind" (Parliamentary Monitoring Group, 2020), two lecturers in the Faculty of Engineering and the Built Environment (FEBE) at the UoT devised a multimodal low-tech remote teaching approach as described below.

On 6 April 2020, all the students (70) registered for the particular qualification were asked to be part of a development team for an MIM teaching intervention to continue the academic programme. At that stage a popular MIM app called WhatsApp was used and 58 students volunteered. From May to July 2020, MS PowerPoint notes that had previously been used to present the curriculum content in face-to-face lectures were subdivided into smaller "bitesized" presentations for an MIM teaching intervention. The original MS PowerPoints was stripped of all unnecessary pictures and a plain white background was used to improve legibility. On average, each MS PowerPoint presentation (lesson) was converted into seven smaller presentations covering all the work included in a particular lesson. The smaller presentations were then converted into PDF documents and an accompanying voice note was recorded to explain each PDF document. Software was used to compress each PDF and voice note to ensure that minimal data would be used by the students who were sent these 
learning materials. The aim was to develop low data usage resources (between $0.1 \mathrm{MB}$ and $8 \mathrm{MB}$ ) to be communicated on a low-tech platform such as Telegram, that could be part of a multimodal teaching strategy. Significantly, throughout the entire process of the MIM teaching intervention development, students were consulted and provided feedback to the lecturers on the resources developed. On 5 May 2020, the development group started using Telegram instead of WhatsApp, due to lecturer perception that the mobile app has better privacy features than WhatsApp. This signified the commencement of "Teaching with Telegram". All lessons for a particular course for semester two (July to November 2020) were delivered via Telegram, as well as informal self-assessments using Telegram's poll function. Formal assessments were however done on the university's learning management system (LMS).

This mixed methods study took place from November 2020 to June 2021. Three separate data collection instruments were used on a target population consisting of one cohort of 70 students. The first data collection instrument was an online survey circulated in November 2020 (response rate $49 \%, n=34$ ) which included 14 Likert scale questions and five openended questions to obtain a general understanding of the students' perceptions of their experience. Following the data analysis of the initial survey (quantitative descriptive statistics of Likert scale questions and qualitative analysis of open-ended questions), a qualitative research instrument (second data collection instrument) was developed. All students were invited to participate in an online focus group interview and six students volunteered. The focus group interview took place in March 2021 and was facilitated by a staff member who was not directly involved in the research. A pre-interview briefing session took place where students were informed of procedures to be followed, as well as the Protection of Personal Information Act (POPIA) and they were asked to give consent. The purpose of POPIA is to protect people from harm by protecting their personal information (Michalsons, 2021). Students were reminded that their participation was voluntary and they could withdraw at any time. Qualitative data were independently analysed by two researchers on this project. A code book with predetermined codes under the themes "redistribution", "recognition" and "representation" was developed before the start of data analysis. However, an inductive approach was also followed as researchers added new codes and allowed new themes to emerge. Recurring themes were identified.

The results of the focus group data analysis were triangulated with the findings of the initial online survey, which led to the development of a second (deductive) online survey that was circulated to the same cohort in June $2021(n=32)$. This third data collection instrument (follow-up online survey) consisted of twenty questions, of which nine were open-ended, to explore the students' perceptions of their experience specifically and deductively along Fraser's (2008) three dimensions. Thus, the follow-up online survey consisted of three main sections. The first section solicited information on student resources (redistribution), the second focused on specific factors that had an impact on them (recognition) while the third gathered information on the students' perceptions on the co-creation aspect of the Telegram teaching intervention (representation).

\subsection{Validity, reliability and limitations}

Alpha Cronbach's coefficient was used to ensure internal validity and reliability of the Likert scale survey questions. The Alpha Cronbach result for all sections of the both online survey instruments of this study were above 0.7 , thus the instrument is considered to be internally valid and reliable. During the focus group interview the same question was asked in different 
ways to facilitate data saturation to promote validity of the focus group component of the study. Data saturation and peer review were the techniques used to ensure qualitative data analysis validity. Moreover, the research design consisting of three separate data collection instruments (two inductive and one deductive) lends itself to imparting external validity since findings of the initial study were verified and validated by the follow-up study. Thereafter the process of triangulation was used to ensure validity of the research findings. A limitation of this study is that data was only collected from students in one department at a UoT and the target population consisted of part-time students only, thus these findings cannot be generalised to all situations at different universities. Ethical clearance for this study was granted through institutional channels.

\section{Findings and discussion}

The findings of the analysis of data obtained from the three data collection instruments, as well as a discussion on them are presented below in the order in which data analysis was done, commencing with initial online survey data analysis, followed by qualitative data analysis and triangulation, and finally the findings of the data analysis of the follow-up online survey.

\subsection{Initial online survey findings and discussion}

A census sample was attempted in order to promote external validity of results; however, of 70 potential research participants, only 34 students completed the initial survey.

\subsubsection{Redistribution}

Notably, $47 \%$ of the research participants reported that in March 2020, at the start of lockdown, they did not have access to an adequate device, stable internet connection and/or sufficient data to continue to participate in class. This situation improved only slightly as lockdown progressed, as in September 2020, a smaller proportion, $28 \%$ of research participants, did not have access to an adequate device, stable internet connection and/or sufficient data. Evaluation of the responses to the open-ended questions (qualitative data) indicated that research participants concurred that Telegram was instrumental in providing quick and easy access to course material that students regarded as very important in lockdown. Most of the research participants $(88 \%)$ felt that in general the learning materials were easy to access on Telegram. Significantly, $77 \%$ of the participants felt that it was easier to learn weekly lesson content using Telegram than if they attended weekly face-to-face lessons, and $74 \%$ of the research participants felt that it was easier to learn weekly content than if they attended weekly webinars (online class meetings). Some responses to open-ended questions explained why, such as "...uses less data, lessons are available in your own time at all times for you to listen to and access (S1-1)" and "Easy to access anywhere, get to see other students' questions which can also assist you (S1-2)". One respondent in particular highlighted the usefulness of Telegram when concurrently having to manage a personal situation, saying "You can access it anytime anywhere, it's convenient. I sat doing my work during hospital visits of my now late grandpa. It helped a lot. (S1-3)"

It is worth noting when research participants were asked to identify disadvantages of using Telegram, none of the drawbacks mentioned were directly relevant to the impact of Telegram on redistribution, such as "...it does not automatically go to the next audio lesson when a lesson finishes (S1-4)". A few respondents felt a disadvantage of the app was that it requires data; however, most participants were satisfied that the app uses less data than webinars. 


\subsubsection{Recognition and representation}

During data analysis of the initial online survey, we observed overlapping areas between Fraser's (2008) second and third dimensions. From our point of view, "recognition" is understood to be an action that is taken to prevent our part-time students from feeling unnecessarily vulnerable or discriminated against due to their personal situations. Simultaneously, we understand "representation" to be adoption of measures to promote participation as full partners in social interaction and giving them an equal voice in community discussions and democratic decision-making. Analysing the data, we noted that fostering "recognition" goes hand in hand with promoting "representation". Seventy-one percent $(71 \%)$ of the research participants reported it was easier for them to engage with the lecturer via Telegram than in face-to-face classes, and $79 \%$ of our research participants reported that it was easier for them to do so than in a webinar. Significantly, $84 \%$ of the research participants reported that it was easier for them to engage with other students on Telegram than in face-to-face classes or webinars. We believe these findings are particularly significant since, especially during the early months of lockdown, acknowledging the student voice became critical for the development of sustainable teaching solutions to complete the academic programme.

With specific reference to the second dimension (recognition), $89 \%$ of the research participants reported that the self-paced nature of the Telegram intervention (being able to do weekly lessons in their own time) was better for them in lockdown than having a weekly faceto-face class or webinar at a set time. In response to an open-ended question in the survey, one student reported that, as an essential service worker and a mother, she was able to keep up with her studies in addition to fulfilling her other responsibilities because Telegram was used to teach. She said "...it worked for me because at times I would miss classes but I was able to come back to the whole class, and actually start from the beginning of the class and gradually get, like I felt like I was in class again. It gave me the opportunity to grasp everything as it was from the lecturer (S1-5)".

\subsection{Qualitative findings from focus group interview and discussion}

\subsubsection{Redistribution}

Exploring "redistribution", data collected from the second data collection instrument (focus group) highlighted that lack of mobile internet data was the primary concern for the participants. Secondary to that was the challenge of connectivity which in most cases existed because of the planned power outages. It was noted by one research participant that "the biggest problem being not enough data and connection (FG1)". Additionally, with children at home using the WiFi and occupying study spaces left our part-time students feeling doubly burdened as explained here: "the fact that everyone was at home, the kids were home so now there was there would actually be problems of data and actually having a space that is quiet enough to work in (FG1)".

Another concern worth noting was the devices and/or mobile phones used by some students were not suited for learning. Data analysis indicated that not all students own laptops or desktops that could be limiting when accessing course material. The following extract from one of the research participants serves as confirmation of this concern: "My expectations is that the material doesn't use much data when you download it and also the material that will be compatible, like when you open it, it must be a document that must be compatible with your phone and it must not be bulky, it must be concise so that it can fit your screen and you can view it (FG2)". 


\subsubsection{Recognition}

Focus group data analysis made it clear that the participants were concerned with time management challenges under the lockdown conditions. Many participants felt that when using the Telegram app, they could manage time better, as stated by one participant: "It also helped me manage my time well because I did not have to travel to the class (FG3)". Another participant concurred: "It helped me to also manage my study time a little bit better and I could retrieve information in my own time and my own space (FG4)".

Further analysis highlighted that the participants had concerns related to the frequent unavailability of the institutional eLearning platform (LMS). Findings suggest there is a need for an additional learning platform that will enable part-time students to access learning material and engage with the course provider from their various remote (rural) locations. This is evidenced by one research participant who stated: "As long as there was information on another platform like Blackboard. They [lecturers] must not be quiet at all. If they can, use at least Telegram (FG4)".

Our study also drew attention to some disadvantages of using the Telegram app. These were related to our students' confidence in traditional teaching methods and perhaps the need for things to "stay unchanged". One participant mentioned "...not being able to pose questions live as in I think the physical, the interaction was always better than the online (FG5)". Keeping in mind that the target population of our study were part-time students, mostly older in age, the data analysis underscored 1) a need for personal interaction, 2) an expectation that the lecturer would respond to questions almost immediately and 3) some students felt overwhelmed by the amount of information provided on the Telegram app. Extracts in support of this deduction are: "...cultural expectation that we attached to instant messaging is that there would be sort of a short period of time in which we respond to each other... (FG4)", "...sort of an expectation because of the word instant messaging, you also have instant reply (FG1)" and "it consumes time in order to decipher the necessary information you may want (FG3)".

\subsubsection{Representation}

Students felt valued when included in decision-making on which MIM teaching tool to use: "there were lecturers that allowed for a broad spectrum of medias [sic] to be used and that was good (FG6)". A further finding uncovered that the students' concerns were acknowledged when deciding on Telegram as an additional teaching tool: "...but remember one of the requirements that we made clear to the lecturer was information needs to be low data (FG4)". The primary objectives of the lecturers on the programme were to continue teaching, engage with the student and further the academic projects. We believe the students became co-creators on the Telegram app which led to the reestablishment of their confidence. This fact was highlighted while analysing data from the focus group interview, when one participant started explaining to the others exactly how the learning material was organised: "it will say part one, part two and whatever and those parts, they are exactly a duplication of your study guide that was given, I am saying it because I was asked to develop an Excel spreadsheet, drawing up all those parts and label it, so umh ja. Using it in conjunction with your study guide (FG1)".

It is worth noting that students appreciated the immediate feedback on their performance, after completing a self-test on Telegram. The MIM tool has a voting feature that allows the lecturer to set up a poll to get the students' view on a particular issue. Moreover, the poll 
feature allows lecturers to give students an opportunity to informally assess themselves, which is evidenced by "You can get a percentage like how you did or what other answers students gave and their percentages and stuff (FG6)" and "Doing quiz which was a nice way of learning also, on top of the quiz I wanted to add voting. We can vote on an issue, there's a feature there that was for voting on a certain issue (FG2)".

The most valuable finding from the research was the ownership and discipline displayed by some of the students, as exemplified by one of the respondents: "But at the same time, on the other hand, I had to cover that up with my own personal study time and that allowed me to understand more than getting spoon-fed by the lecturer if I would say that way, because I had to put more time in my work and it made me to - everything that l'm learning (FG2)".

\subsection{Triangulation of data from first and second data collection instruments}

Evaluation of the findings of the initial online survey together with those of the focus group interview allowed us to confirm that our students (research participants) share the same challenges as the general South African student population as reported by Shoba (2020). These include restricted access to data, as well as inadequate devices to continue their studies. This reaffirms the importance of "redistribution" in our context. Moreover, triangulation also highlighted that aside from restricted data and inadequate devices, the lack of a conducive location to study is also a significant barrier for our students. Related to "recognition", this finding is foregrounded by general attributes of part-time students, which is they typically have families and family responsibilities, in addition to trying to complete their studies.

Continuing on the theme of "recognition", the triangulation of our data showcased tensions experienced by our students as a result of conflicting priorities of being part-time students. During the evaluation of qualitative responses, we noted the sense of urgency our students exhibit towards completing their studies, which could be attributed to them being older students with responsibilities (Lee, 2017). In addition, there seemed to also be a sense of appreciation for being able to continue during lockdown because of the Telegram app. Triangulation also allowed us to verify some of the specific needs articulated by research participants, such as the need for flexibility and simplicity over complexity. Furthermore, the findings of our initial analysis led us to deduce that our students particularly valued the self-paced nature and latitude that our Telegram intervention permitted, considering that they had other domestic and professional responsibilities, aside from just being students.

Triangulation confirmed that in our context "recognition" is closely related to "representation". Our findings directed a spotlight on the importance of student consultation while developing our intervention. We also noted survey results on student perceptions of the importance of interactions were aligned with student responses on the same subject in the focus group. From this we deduced that Telegram was a valuable tool, not only for the delivery of curriculum content but also for revision and communication between lecturers and students, and students with each other. Survey and focus group findings also confirmed that in the absence of traditional avenues for interaction, Telegram not only provided a platform for participation, but students also perceived that participation was easier.

We surmised that if our students (and their needs) were not duly "recognised" it would be challenging for them to interact and participate and therefore be appropriately "represented" in the classroom environment. We deduced that "recognition" also entails, in addition to 
mere acknowledgment of characteristics and requirements that are unique to them, action associated with prevention of misrecognition, such as soliciting their requirements, before planning a teaching intervention.

Importantly, during the process of triangulation, shortfalls in our initial data collection instruments became apparent, when it was realised that we could not conclusively make a deduction on whether our Telegram intervention facilitated participatory parity in our classroom environment. While the general descriptive findings were of great interest to us, these findings raised further questions about the extent of social justice in our practice. Thus, the results of the triangulation of our initial online survey and focus group interview data served as a foundation for us to develop a follow-up data collection instrument, namely the follow-up online survey that we used to deductively confirm our initial findings. Findings of data collection and a discussion on these findings are presented in the section that follows.

\subsection{Follow-up online survey findings and discussion}

As with the initial survey, a census sample was also attempted in order to promote external validity of results; however, of the 70 potential research participants, only 32 students completed the follow-up survey.

\subsubsection{Redistribution}

In relation to Fraser's (2008) first dimension, $75 \%$ of the research participants confirmed that Telegram improved their ability to continue studying during lockdown citing affordability as the reason. Another recurring reason, which at face value seems unrelated to economic factors, is simplicity of use and ease of access to course notes. This validates initial survey findings, as in both surveys more than $80 \%$ of participants offered simplicity as a reason for preferring Telegram over synchronous webinars. Considering that a plethora of technology solutions are available that also provide simple and easy access to lessons and learning material, we believe that a statement from one research participant explains how, in this case, simplicity and easy access to course notes is related to economic factors. He attested that "low data usage" was a priority for him and, therefore, more sophisticated but more expensive technology would have been problematic for him. Thus, Telegram is a feasible, low-tech and more desirable alternative to more sophisticated and expensive technology platforms.

We noted, however, that despite the Telegram intervention being valued by students, there were some students who continued to struggle due to factors that are out of our control, as illustrated by this response to an open-ended question: "Although initially it was difficult since I did not have a proper phone I extremely struggled [sic] due to data purposes and device not having sufficient space to install Telegram. However, at some point my life transformed. I got an internship and I bought a new device and started using my workplace WiFi to catch up with my school work. Telegram was a better app to use as it charged less for data. (S2-1)"

\subsubsection{Recognition}

With respect to Fraser's (2008) second dimension on "recognition" which is concerned with institutionalised hierarchies of cultural value that prevent members of a community from interacting in terms of parity, one research participant highlighted some challenges associated with being a part-time student. Aside from general challenges such as limited bursary opportunities, our UoT did not prioritise purchasing data for part-time students during lockdown. This student was invited to apply for mobile internet data; however, when this 
study took place a year later, the student still had not received the data. Thus, this student in particular perceived the Telegram app to be beneficial since very little mobile internet data was required when using it.

Moreover, in addition to an appreciation for the flexibility afforded by the app due to the self-paced user design of the Telegram teaching intervention, the feature of having quick and easy access to revisable class notes and recordings, independent of the institution's eLearning platform (LMS), was another significant advantage. Two research participants highlighted the challenges associated with being reliant on the UoT's ICT service department to resolve problems, such as server downtime and technical issues, which they felt was a common occurrence at the UoT. Being plagued with technical problems such as server downtime has an impact on study time. Drawing from the results of the follow-up online survey, as well as the focus group interview, we understand that time management is a critical concern for our students in particular, who struggle to juggle different priorities related to academic life, work and family. We concluded that, in this regard, the Telegram intervention was a beneficial tool for our students.

\subsubsection{Representation}

Concerning the third dimension, we deduced that, in general, our students considered Telegram to be a useful tool, giving them a voice they might not have had in a face-to-face class or webinar. Significantly, $84 \%$ of our research participants confirmed that they felt more "represented" when using Telegram to interact with the lecturer or other students. Examples of open-ended responses that confirm this are: "Everyone had a chance to communicate effectively" and "I'm a shy person and speaking up in huge crowds so Telegram gave me the platform to be able to speak up without having attention on me (S2-2)".

We found it interesting that, although most research participants felt represented when using the Telegram app for learning, as illustrated by this excerpt: "In class you only have that specific time to ask questions unlike Telegram you can ask questions anytime (S2-3)", some research participants suggested that Telegram should only be used for communication, as opposed to for teaching, learning and communication, as illustrated by these quotes: "Telegram is good for communication and loading notes but Blackboard and online lectures are sufficient. Telegram can be used for communication (S2-4)" and "Telegram is good for extra learning activities and information sharing. However, it should not replace a more formal platform like Blackboard (S2-5)".

A further point of interest was that research participants reported feeling "represented" when asked to be co-creators and participate in the design of the Telegram intervention at the commencement of lockdown. Open-ended questions probing this returned responses such as "Made me feel welcome and important... (S2-6)", "Felt part of the team (S2-7)", "It's always liberating (S2-8)" and "Great as everyone was given a chance to voice out their opinions (S2-9)". When asked why participants felt that way, they answered: "...it meant that my view mattered", "[Being] Part of the solution and more comfortable to participate in discussions" (S2-6), "...I was the one that was going to use telegram for teaching and learning so for the lectures to ask my opinion and input that was good (S2-8)", "It means a lot to be involved (S2-7)" and "My voice is listened to and I feel included (S2-9)". Significantly, 100\% of the research participants reported feeling as if they were partners in the planning process with lecturers as well as fellow students. From this, we deduce that our students perceived our practices when adopting Telegram as a teaching tool during lockdown, as socially just. 


\section{Conclusion}

The limitation of our study is that data was only collected from part-time students in one department at a UoT and therefore the findings cannot be generalised to all situations at different universities. This study however, showcased how the Telegram app, which was originally designed for cost-effective communication, could effectively be used to deliver curriculum content and engage with students in a low-tech, low-cost/low-data usage manner, and consequently widen access to education, thereby promoting inclusivity. The app possesses features that make it suitable for the delivery of a self-paced curriculum, which we found is particularly valuable to part-time students. Moreover, the app promotes interaction between peers at the same level. Another significant feature of the app is the ability to conduct anonymous polls, which give students an opportunity to express themselves without having to fear potential negative repercussions. The Telegram app itself does not confer participatory parity to an online classroom environment; however, the manner in which the app's features are utilised makes this possible.

For us, Fraser's (2008) conception of social justice served as a good point of departure and a useful lens to examine and understand our practices - how technologies such as the Telegram app can be used as a tool to achieve participatory parity. Participatory parity in our context was providing our students with an inclusive and enabling learning experience, during a disruptive and apprehensive time in world history. We acknowledge that the Telegram app is not a silver bullet; however, when used in a socially just manner, it can be a powerful pedagogical tool.

\section{References}

Agherdien, N. 2020. COVID-19: Towards actions during uncertainty. Available at http://heltasa. org.za/covid-19-towards-action-during-uncertainty/ [Accessed 14 April 2020].

Bao, W. 2020. COVID-19 and online teaching in higher education: A case study of Peking University. Human Behaviour and Emerging Technologies, 2(2): 113-115. https://doi. org/10.1002/hbe2.191

Bere, A. 2012. A comparative study of student experiences of ubiquitous learning via mobile devices and learner management systems at a South African university. Proceedings of the $14^{\text {th }}$ Annual Conference on World Wide Web Applications. Durban, South Africa: Cape Peninsula University of Technology.

Bozalek, V. 2016. Participatory parity and emerging technologies. In M. Walker \& M. Wilson-Strydom (Eds.). Socially just pedagogies, capability and quality in higher education: A global perspective (pp. 89-109). London: Palgrave MacMillan. https://doi. org/10.1057/978-1-137-55786-5_5

Fraser, N. 2008. Abnormal justice. Available at http://www.fehe.org/uploads/media/Fraser_ Abnormal_Justice_essay.pdf [Accessed 12 June 2020]. https://doi.org/10.1086/589478

Fataar, A. 2020. Teachers courageously confront the challenge of teaching during the COVID-19 pandemic. Available at https://www.sun.ac.za/english/Lists/news/DispForm. aspx?ID=7452 [Accessed 16 July 2021].

Gachago, D. \& Cupido, X. 2020. Designing learning in unsettling times. Available at http:// heltasa.org.za/designing-learning-in-unsettling-times/ [Accessed 27 March 2020]. 
Gon, S. \& Rawekar, A. 2017. Effectivity of e-Learning through WhatsApp as a teaching learning tool. MVP Journal of Medical Sciences, 4(1): 19-25. https://doi.org/10.18311/mvpjms. v4i1.8454

Greene, J. 2020. How (not) to evaluate teaching during pandemic? The chronicle of higher education. Available at https://www.chronicle.com/article/How-Not-To-EvaluateTeaching/248434 [Accessed 31 August 2020].

Gronseth, S. \& Zhang, H. 2018. Advancing social presence, community, and cognition through online discussions. In M. Marmon (Ed). Enhancing social presence in online learning environments (pp. 117-140). Hershey: IGI Global. https://doi.org/10.4018/978-1-5225-3229-3. ch006

Huang, R.H., Liu, D.J., Thili, A., Yang, J.F. \& Wang, H.H. 2020. Handbook on facilitating flexible learning during educational disruption: The Chinese experience in maintaining undisrupted learning in COVID-19 outbreak. Beijing: Smart learning institute of Beijing Normal University.

Iqbal, M.Z., Alradhi, H.I., Alhumaidi, A.A., Alshaikh, K.H., AlObaid, A.M., Alhashim, M.T. \& AlSheikh, M.H. 2020. Telegram as a tool to supplement online medical education during COVID-19 Crisis. Acta Informatica Medica, 28(2): 94-97. https://doi.org/10.5455/ aim.2020.28.94-97

Kauppi, S., Muukkonen, H., Suorsa, T. \& Takala, M. 2020. I still miss human contact, but this is more flexible - Paradoxes in virtual learning interaction and multidisciplinary collaboration. British Journal of Educational Technology. 51(4): 1-16. https://doi.org/10.1111/bjet.12929

Kukulska-Hulme, A., Pettit, J., Bradley, L., Carvalho, A., Herrington, A., Kennedy, D. \& Walker, A. 2011. Mature students using mobile devices in life and learning. International Journal of Mobile and Blended Learning, 3(1): 18-52. https://doi.org/10.4018/jmbl.2011010102

Lee, N.E. 2017. The part-time student experience: Its influence on student engagement, perceptions, and retention. Canadian Journal for the Study of Adult Education, 30(1): 1-18.

Leibowitz, B., Swartz, L., Bozalek, V., Carolissen, R., Nicholls, L. \& Rohleder, P. (Eds.). 2012. Community, self and identity: Educating South Africa university students for citizenship. Cape Town: HSRC Press.

Leibowitz, B. \& Bozalek, V. 2016. The scholarship of teaching and learning from a social justice perspective. Teaching in Higher Education, 21(2): 109-122. doi: $10.1080 / 13562517.2015 .1115971$

Lim, M. 2020. Educating despite the COVID-19 outbreak: Lessons from Singapore. Available at https://www.timeshighereducation.com/blog/educating-despite-covid-19-outbreak-lessonssingapore\#survey-answer [Accessed 30 August 2020].

Mahmood, S. 2021. Instructional strategies for online teaching in Covid-19 pandemic. Human Behaviour \& Emerging Technologies, 3: 199-203. https://doi.org/10.1002/hbe2.218

Michalsons. 2020. Protection of personal information act summary. Available at: https://www. michalsons.com/focus-areas/privacy-and-data-protection/protection-of-personal-informationact-popia [Accessed 14 September 2021].

Nitza, D. \& Roman, Y. 2016. WhatsApp messaging achievements and success in academia. International Journal of Higher Education, 5(4): 255-261. https://doi.org/10.5430/ijhe.v5n4p255 
Ogara, S., Koh, C. \& Prybutok, V. 2014. Investigating factors affecting social presence and user satisfaction with mobile instant messaging. Computers in Human Behaviour, 36: 453-459. https://doi.org/10.1016/j.chb.2014.03.064

Opotow, S. 2011. Social injustice. In D.J. Christie (Ed.). The Encyclopaedia of Peace Psychology. Malden: Blackwell Publishing Ltd. https://doi.org/10.1002/9780470672532. wbepp256

Oyewole B., Animasahun V. \& Chapman H. 2020. A survey on the effectiveness of WhatsApp for teaching doctors preparing for a licensing exam. PLOS ONE, 15(4): e0231148. https://doi. org/10.1371/journal.pone.0231148

Parliamentary Monitoring Group. 2020. COVID-19 response: University \& TVET plans for 2020 academic year; DSI work on COVID-19 with Minister. Available at https://pmg.org.za/ committee-meeting/30102/ [Accessed 31 August 2020].

Patnaik, S. \& Swartz, B. 2020. Mobile instant messaging applications - Online teaching during COVID19. digiTAL2020 International Conference on teaching, assessment and learning in the digital age. Virtual conference, 3-4 December 2020.

Putri, S. \& Elihami, E. 2021. The concept of andragogy and pedagogy: e-Learning model during COVID19 pandemic, Jurnal Edukasi Nonformal, 2(1): 18-24.

QS. 2020. The impact of the corona virus on global higher education. Available at https://www. qs.com/portfolio-items/the-impact-of-the-coronavirus-on-global-higher-education/ [Accessed 30 August 2020].

Rowe, M. 2020. Universal principles of learning task design. Crisis edition. Available at http:// heltasa.org.za/universal-principles-of-learning-task-design-crisis-edition/ [Accessed 17 April 2020].

Sari, F.M. 2017. Maximizing Telegram application for teaching reading. The 4th UAD TEFL International Conference, UAD Yogyakarta. https://doi.org/10.12928/utic.v1.171.2017

Shoba, S. 2020. As South Africa goes into lockdown, the higher education department prepares for online learning. Available at https://www.dailymaverick.co.za/article/2020-0324-as-south-africa-goes-into-lockdown-higher-education-department-prepares-for-onlinelearning/ [Accessed 31 August 2020].

Silver, L. Smith, A., Johnson, C., Jiang, J., Anderson, M. \& Rainie. L. 2019. Use of smartphones and social media is common across most emerging economies. Available at https://www. pewresearch.org/internet/2019/03/07/use-of-smartphones-and-social-media-is-commonacross-most-emerging-economies/ [Accessed 6 August 2021].

So, S. 2016. Mobile instant messaging support for teaching and learning in higher education. The Internet and Higher Education, 31: 32-42. https://doi.org/10.1016/j.iheduc.2016.06.001.

Tang, Y. \& Hew, K.F. 2017. Is mobile instant messaging (MIM) useful in education? Examining its technological, pedagogical, and social affordances. Educational Research Review, 21: 85-104. https://doi.org/10.1016/j.edurev.2017.05.001

Timmis, S. 2012. Constant companions: Instant messaging conversations as sustainable supportive study structures amongst undergraduate peers. Computers and Education, 59(1): 3-18. https://doi.org/10.1016/j.compedu.2011.09.026 
van Aardt, P. \& Sibanda, B. 2021. During lockdown, South African students wrote a book about "a world gone mad". The conversation. Available at https://theconversation.com/duringlockdown-south-african-students-wrote-a-book-about-a-world-gone-mad-161502 [Accessed 10 August 2021].

Viner, R., Russell, S., Croker, H., Packer, J., Ward, J., Stansfield, C. \& Booy, R. 2020. School closure and management practices during coronavirus outbreaks including COVID-19: A rapid systematic review. Review, 4: 397-404. https://doi.org/10.1016/S2352-4642(20)30095-X

World Health Organization. WHO. 2020. World Health Organization. Available at https:// www.who.int/southeastasia/outbreaks-and-emergencies/novel-coronavirus-2019. [Accessed 10 August 2021]. 